\title{
Can Facebook be an Effective Tool in Disseminating Environmental Messages to Society? A Case Study of 12 Environmental Non-Governmental Organisations (ENGO) in Malaysia
}

\author{
Nur Nasliza Arina Mohamad Nasir ${ }^{1}$, Jamilah Ahmad ${ }^{2}$ \\ ${ }^{\prime}$ (School of Communication, Universiti Sains Malaysia, Malaysia) \\ ${ }^{2}$ (School of Communication, Universiti Sains Malaysia, Malaysia)
}

\begin{abstract}
Environmental issues are not new in Malaysia. These issues are always associated with society because of there is lack of civic mindedness among certain quarters of the Malaysian society. Therefore, it is very important to enhance society awareness and understanding towards the importance of preserving and conserving the environment. In this era of globalisation, Facebook that triggers worldwide phenomenon is considered as the most popular communication medium and widely used by Malaysians. As of November 2012, the number of Malaysians who use Facebook was 13,461,860. Considering the huge number of Facebook users in Malaysia, it is very important for ENGOs to use Facebook as a delivery medium of information in disseminating environmental messages to the society. With regard to this study, it was conducted to investigate the role of Facebook in helping ENGO to disseminate environmental messages to society, to identify the effectiveness of two way communication between ENGOs and society through Facebook and to gauge the effectiveness of Facebook in delivering environmental messages to society. This study employed face-to-face indepth interviews in order to get the insight from 12 ENGOs'. The data was analysed using thematic analysis. The findings of this study indicate that, the effectiveness of Facebook in disseminating environmental messages to society relies on several factors such as the target audiences identified by ENGOs, ENGOs' objectives and purposes as well as the number of people that 'like' ENGOs' Facebook pages .
\end{abstract}

Keywords: Environment, Environmental Non-Governmental Organisation (ENGO), Facebook, Society, Thematic Analysis.

\section{Introduction}

Environmental issues have been widely discussed and debated by Malaysians at all levels in recent years. The Malaysian government takes serious measures to ensure better environmental condition in the country (Juliana and Nur'Aainaa, 2012). Since its independence, Malaysia has enjoyed a very favourable socioeconomic development and has received international appreciation, but unfortunately the development and irresponsible attitude of the people has brought some negative effects on the environment and the quality of human life (Jamilah et al., 2011). In Malaysia, environmental problems are becoming more severe with each passing year and these issues are frequently discussed within the society (Adnan et al., 2012). According to Osbaldiston and Schott (2012), on a global scale, environmental problems include climate change, armed conflicts over resources especially oil and pollution of the air, water, and soil. The major impacts of these problems are drastic changes to quality and quantity of all life, as well as human life.

Apart from natural disasters, society can be categorised as the main contributor to the environmental crisis. The uncontrolled human activities indirectly contribute to various natural disasters such as flash floods, landslides and forest fires (Zul and Zailan, 2012). Besides, the environment is also severely damage by excessive and improper use of natural resources by society. This negatively affects all living creatures including human beings (Birsen and Birsen, 2012). Realising the danger, many parties including government agencies and non-governmental organisations (NGOs) have come together to join effort in ensuring better environment for the future. Rohani et al. (2010) stated that, non-governmental organisations (NGOs) in Malaysia are non-profit organisations run by volunteers and have many roles and the role of environmental non-governmental organisations (ENGO) is to protect the environment.

To disseminate environmental messages to society, environmental non-governmental organisations (ENGO) play an important role in communicating environmental issues to the society and also in educating them on matters related to the environments. Environmental non-governmental organisations (ENGO) worldwide known for their prominence in dealing with environmental issues as well as in influencing decisionmaking and policies related to the environment (Rusli and Lee, 1999). Therefore, the use of appropriate delivery medium of information is necessary to ensure that ENGOs deliver environmental messages effectively to the 
society and at the same time enlighten them about the importance of protecting the environment. One of the delivery mediums of information that can be used by ENGOs are Facebook. This is because, Facebook is considered as the most popular communication medium and widely used by the society nowadays. Apart from that, Facebook is also considered as an effective medium of communication if it is used positively (Mohd Shamsuriyadi, 2010).

Facebook has not only sparked a phenomenon in Malaysia, but it has also generated a worldwide phenomenon. Facebook has succeeded in forming its own territory and this is evidenced in the huge number of users that comprise of people with different ideologies, skin colours, religions and ethnicities (Berita Harian, 2010). As stated by Das and Sahoo (2011), Facebook was founded by Mark Zuckerberg' and it was initially launched for Harvard students. Today Facebook is considered as the most used social networking site by users worldwide. There are more than 800 million active users are using Facebook around the world through the use of 70 languages. Majority of the users are adults including parents and teenagers represent only a minority population on Facebook (Collier and Magid, 2012). The usage of Facebook is not limited to individuals, but the medium is also used by different groups such as government agencies, non-governmental organisations and special interest groups to deliver specific messages to their intended audiences.

In Malaysia, Facebook continues to be the most popular social networking site used by Malaysians. The usage of Facebook is more than 5.1 million and 5.7 visitors per month. Facebook also has taken over the position of Friendster that once dominated online social networking in Malaysia and other countries in the Southeast Asia region (Siti Ezaleila and Azizah, 2010). Based on the statistics released by Socialbakers (2012), an online market research company from the U.S., as of November 2012, the number of Malaysians who joined Facebook has reached to $13,461,860$ users and this placed Malaysia on the $18^{\text {th }}$ position on the ranking of countries with the highest users of Facebook in the world. The Facebook penetration in Malaysia was $47.61 \%$, while as much as $84.19 \%$ of them are the number of internet users. In the last six months alone, the number of Facebook users in Malaysia has increased to more than 1,221,860 (Socialbakers, 2012).

Malaysia's position at $18^{\text {th }}$ in the ranking of countries with the highest users of Facebook shows that, the social networking site is not only popular in countries with larger population like the United States and India, but it is also popular in countries with smaller population like Malaysia. As reported by Alexa.com, web Information Company from the U.S., since 2010 until now, there are 100 sites that are frequently visited by internet users in Malaysia. Facebook is placed first among the sites making it as the most accessed by Malaysians.

In brief, Facebook is a social networking site that allows its users to meet with each other and interact, share photos, videos and other information. Facebook users include friends, family members, colleagues and other individuals who are subscribed to the social networking site (Gunter, 2011). According to Susilo (2008), Facebook has brought in a lot of new features that help to make Facebook as an important part of daily life. For instance, Facebook has introduced a new blog subscription services where users can join their favourite blog and enjoy all its content without having to leave the site. Susilo (2008) added that, Facebook is specially designed to focus on creating and maintaining real relationships and building the sense of community.

According to Lee et al. (2012), Facebook allows its users to communicate with each other in different forms including by browsing other users' profiles, sharing of status updates, posting comments, sharing photos, chatting, sending private messages and playing online games. Facebook also enables its users to present themselves in an online profile, accumulate friends who can post comments on each other's pages and view each other's profiles (Sheldon, 2008). In addition, Shih (2011) informed that, one of the things that make Facebook better compared to other social networking sites is its privacy settings. This is evidenced as Facebook provides privacy settings options to its users where photos, profile information or personal information can be shared only with friends, certain networks or specified individuals.

According to Mazer et al. (2009), Facebook is a great interactive virtual social network. It provides users with a function to easily search and view any other user's profile within the Facebook network, to have a discussion-board like device that enables users to discuss and it also allows users to post messages on their friends' walls. It is also important to note that, the use of Facebook is no longer just for personal interaction, but Facebook has grown into a medium to transmit information, conduct business, education and sharing of photos and videos (Jauhariatul and Jamilah, 2011). Facebook also allows users to use the message boards and discussion wall to send announcements and asking questions (Carrera et al., 2008).

Considering its huge number of users in Malaysia as well as the potentials on offer, it is no doubt that Facebook is considered as an important delivery medium of information used by ENGOs to disseminate information and environmental messages to society. This is explained by Mohd Shamsuriyadi (2010) who indicated that, Facebook is the medium of online communication that is most used by Malaysians, it has the potential to become an effective medium of communication if positively used. Considering the potentials of Facebook and also its popularity as the most popular preferred medium of online communication in Malaysia, 
the researchers wanted to see to what extent Facebook can help ENGO in disseminating environmental messages effectively to the society.

\section{Methodology}

This study employed face-to-face in-depth interviews in order to get the data from 12 ENGOs that had been identified earlier. The main rationale for employing face-to-face in-depth interviews in this study was due to the needs to gather in-depth data from the respondents related to the effectiveness of Facebook in disseminating environmental messages to the society.

\subsection{Selection of ENGO's}

There are many ENGOs in Malaysia who strive for environmental issues, but only 12 ENGOs that were involved as samples in this study. They were selected based on the purposive sampling. Purposive sampling refers to sampling that involves participants who have specific characteristics or features (Coyne, 1997). The selection of the 12 ENGOs in this study was based on the following characteristics; (1) ENGOs that are registered under Malaysian Environmental NGO's (MENGO); and (2) ENGOs that use Facebook as a medium in delivering environmental messages to society. The 12 ENGOs are Malaysian Nature Society (MNS), Sahabat Alam Malaysia (SAM), Wetlands International Malaysia, Reef Check Malaysia, Sabah Wetlands Conservation Society (SWCS), World Wide Fund for Nature Malaysia (WWFM), Centre for Environment, Technology \& Development Malaysia (CETDEM), Ecoknights, Partners of Community Sabah (PACOS), Water Watch Penang (WWP), Global Environment Centre (GEC) and Environmental Management and Research Association of Malaysia (ENSEARCH).

\subsection{Data collection methods}

Face-to-face in-depth interviews were conducted with respondents who represented ENGOs. The respondents who represented ENGOs were person in-charge of the Facebook account of their respective organisation. All interviews were recorded using digital audio recorder. Information provided by the respondents during interviews was also written down on paper. All the data obtained from the respondents were analysed using thematic analysis.

\subsection{Interview design}

The interviews were conducted based on three main questions. The three main questions are: (1) to what extent can Facebook help in disseminating environmental messages to society; (2); how do a two way communication between ENGOs and the society through Facebook help ENGOs to enhance the content of environmental messages in the future; and (3) do environmental messages disseminated through Facebook gives an impact to society.

The interview questions were designed based on the five principles of Dialogic Communication Theory founded by Martin Buber. The five principles are the usefulness of information, the dialogic loop, ease of the interface, the generations of return visits and the rule of conversation of visitors. The usefulness of information refers to the dissemination of information that is useful to society and intends to persuade and attract the society interest to participate in organisation activities. It also intends to increase society awareness of the existence of the organisation in society itself.

The dialogic loop involves interaction between the society and the organisations. In this case, both parties are required to cooperate with each other in order to give and share the information. If they are not cooperating with each other, the interaction that exists between them is not going to give any meaning. Ease of the interface refers to the user are given enough time to visit the Facebook page. A Facebook page that is not interesting or not user-friendly may results in reduced visits and lesser following people visiting the Facebook page in the future.

The rule of conversation involves various ways and strategies that should be applied by organisations in order to ensure that Facebook users who come across their page will return visits again and eventually become loyal visitors. More importantly, they need to be able capture Facebook users to follow their page. In this regard, return visits refer to the repeated interactions that take place between the organisations and Facebook users who visit their page. Important consideration like time and trust should be prioritised by organisations in order to ensure that Facebook users will continue to visit their page repeatedly and become followers.

From the theoretical perspective, these five principles focus on the dialogue that is in a form of interpersonal communication as an effective tool to benefit both parties. The role of Dialogic Communication Theory in this study was to know, understand and predict the relationship between the society and ENGOs through their interaction to increase society awareness on the importance of preserving and conserving the environment. 


\subsection{Data Analysis}

In this study, the data was analysed using thematic analysis method. Thematic analysis is a method used for identifying, analysing and reporting patterns which refer to the 'themes' within data. Besides that, it also minimally organises and describes data set in (rich) detail (Braun and Clarke, 2006). In order to analyse data using thematic analysis, this study followed the six processes in thematic analysis as suggested by Braun and Clarke (2006). The six processes are; (1) familiarising yourself with your data; (2) generating initial codes; (3) searching for themes; (4) reviewing themes; (5) defining and naming themes and (6) producing the report.

\section{Results and discussion}

The study investigate three research questions that are: (1) to what extent can Facebook help in disseminating environmental messages to society; (2) how do a two way communication between ENGOs and the society through Facebook help ENGOs to enhance the content of environmental messages in the future and (3) do environmental messages disseminated through Facebook gives an impact to society.

\subsection{To what extent can Facebook help in disseminating environmental messages to society?}

There are a variety of responses from respondents about the ability of Facebook in helping ENGOs to disseminate environmental messages to the society. The participating ENGOs stated that, Facebook is able to reach a lot of people in delivering environmental messages to society (WWP, Reef Check Malaysia, SWCS, Wetlands International Malaysia, WWFM, Ecoknights \& PACOS), make the delivery of environmental messages easy and effective (SAM, ENSEARCH, CETDEM, Ecoknights \& Reef Check Malaysia), accelerate the process of delivering environmental messages to the society (PACOS) and help ENGOs to save on the organisational cost because the usage of Facebook is free (Reef Check Malaysia \& WWFM). In addition, the participating ENGOs also stated that, Facebook is useful in a way that it can be used to help ENGOs to highlight and focus on important issues, assist in the process of message repetition (GEC), help deliver an accurate and detail information to the society (SAM) and become a support medium to other mediums that are used by ENGOs (WWFM).

In term of the ability of Facebook to share information with the society, eight of the participating ENGOs stated that, it is at the low level and it only happens sometimes (SWCS, WWP, GEC, CETDEM, ENSEARCH, PACOS, WWFM \& Wetlands International Malaysia). This is due to the fact that ENGOs who are only always giving and sharing the information with society but a very little information that giving and sharing by society with the ENGOs. Members of the society are more inclined to 'share' and 'like' the information posted by ENGOs on Facebook rather than providing or sharing their information with ENGOs. However, four of the participating ENGOs stated that, the ability of Facebook to share information with the society is at high level and it happens all the time. Both ENGOs and the society provide and share useful information with each other using Facebook (SAM, MNS, Ecoknights \& Reef Check Malaysia).

All of the participating ENGOs reported that, besides allowing them to share and disseminate environmental messages to the society, Facebook also allows them to provide various features in their Facebook page in order to facilitate the society to see and understand the message. The features provided by ENGOs on their Facebook pages like allowing users to share information at any time (WWP, GEC \& Ecoknights) and to provide names and contact detail of the individuals who can be contacted for further information (ENSEARCH). In addition, the features provided by ENGOs also include detailed insights about the environmental issue (GEC, SAM, WWP, WWFM, ENSEARCH, PACOS, SWCS, MNS, CETDEM, Ecoknights, Reef Check Malaysia \& Wetlands International Malaysia).

In general, the participating ENGOs acknowledged that, Facebook is useful as it can help them to disseminate environmental messages effectively to the society. It is important however to maximise the use of Facebook for this purpose. This is indicated by many of the participating ENGOs who believed that, they need to maximise the use of Facebook in the future because at present it is still at a moderate level. At present, these ENGOs only use basic applications that are available on Facebook and they strive to improve from time to time. In comparison to other ENGOs, MNS's use of Facebook is at a high level. This is evidenced from the way they maximise the use of Facebook. MNS utilise almost every application available on Facebook to make their page interactive. MNS strongly believe that Facebook can help them to effectively deliver environmental messages to the society.

\subsection{How do a two way communication between ENGOs and the society through Facebook help ENGOs to enhance the content of environmental messages in the future?}

According to all of the participating ENGOs, the communication relationship between them and the society through the use of Facebook runs very smooth and it is always under controlled. They also reported that, they always strive to maintain good relationship with the society by providing accurate and up-to-date information relating to the environmental issues (SAM, WWP, MNS, GEC, ENSEARCH, PACOS, SWCS, 
WWFM, CETDEM, Ecoknights, Reef Check Malaysia \& Wetlands International Malaysia). To ensure that good relationship with their stakeholders is maintained, ENGOs avoid bringing up or touching sensitive issues related to politics (GEC, PACOS, SAM \& MNS), custom affairs and community's way of life (PACOS).

It is through the two way communications that occur between ENGOs and the society, that they manage to gather information about environmental issues from the public. Public's opinion about these issues are posted and discussed on ENGOs Facebook pages. Generally, ENGOs take public's opinions on their Facebook pages positively (SAM, WWP, MNS, GEC, CETDEM, ENSEARCH, PACOS, SWCS, WWFM, Ecoknights, Reef Check Malaysia \& Wetlands International Malaysia). Public's opinions will be strongly considered and used if they are deemed appropriate by ENGOs (GEC, MNS, WWP, SWCS, SAM, CETDEM, WWFM \& Wetlands International Malaysia). ENGOs also take public's opinions to improve the environmental messages in the future by tailoring the messages with the need and interest of society (PACOS, ENSEARCH, Ecoknights, and Reef Check Malaysia). This is because, the society will be more attracted and interested to know and accept the environmental messages that meet their interests and needs because they assumed that it is important to apply in their daily lives.

In ensuring good communication relationship between them and the society through the use of Facebook, ENGO's try their best to interact with the society frequently so that closer relationship can be forged. The frequency in communicating with the society through Facebook is different from one ENGO to another. For instance, for GEC and WWP, the frequency in communicating with the society through Facebook is on a weekly basis (once a week) while for MNS, it is on a daily basis (three times per day). As for SWCS and CETDEM, the frequency in communicating with the society depends on the issues and activities that are organised by the organisation. For ENSEARCH, communication occurs on a monthly basis (three to four times per month). The frequency in communicating through Facebook with the society for SAM is depends on the commitment of the personal in-charge and the feedbacks they receive from the society. While for PACOS, it depends on the activities that are organise by the organisation as well as their accessibility to Facebook. For Ecoknights, WWFM and Reef Check Malaysia, the frequency in communicating with the society through Facebook is on a daily basis while for Wetlands International Malaysia, it is depends on the activities that are organised by the organisation as well as the information that need to be delivered to the society.

Overall, ENGOs regard the two way communications that occur between them and the society through the use of Facebook is useful as it helps them to improve on the environmental messages in the future. Through the two way communications, ENGOs can find out the interests and opinions of the public related to the environmental issues. Most importantly, the two way communications can help ENGOs to improve on their effort to provide information and environmental messages that are interesting, creative and effective.

\subsection{Do environmental messages disseminated through Facebook gives an impact to society?}

According to all of the participating ENGOs, in collecting and disseminating environmental messages to the society, they prefer to focus on the environmental issues that are directly related to their organisations. For example, PACOS mainly focuses on the issue related to the community management towards the environmental, while for Wetlands International Malaysia, they concentrate on the issue of the conservation and wise use of wetlands. For MNS, they are concerned with the issues related to environmental damage. Other ENGOs such as GEC and Ecoknights concentrate on sustainable life, ENSEARCH on the environmental management, WWFM on the preservation of the environment including animals, SAM on human rights and environment, WWP on water conservation, Reef Check Malaysia on the preservation and conservation of coral reefs, SWCS on the environmental education and CETDEM on sustainable development.

All of the participating ENGOs reported that, comments and feedbacks posted by the stakeholders on their Facebook pages are generally very positive and encouraging (Ecoknights, Wetlands International Malaysia, ENSEARCH, SAM, SWCS, WWP, MNS, GEC, CETDEM, PACOS, WWFM \& Reef Check Malaysia). They also indicated that, environmental messages disseminated through Facebook have the potential to give positive impact to the society depending on several factors such as the target audiences identified by ENGOs (ENSEARCH, PACOS, MNS, Reef Check Malaysia, WWFM, SAM, SWCS, Ecoknights \& CETDEM), ENGOs' objectives and purposes (Reef Check Malaysia, MNS, Ecoknights \& PACOS) as well as the number of people that 'like' ENGOs' Facebook pages (GEC, MNS, PACOS, WWP, Ecoknights \& Wetlands International Malaysia).

Different message delivery strategies are used by ENGOs in their effort to ensure environmental messages that are delivered through Facebook give positive impact to the society. These strategies include giving implicit messages to encourage the public to think (CETDEM), using the persuasive approach and not force (Wetlands International Malaysia), customising messages by target audience (PACOS) and providing evidence to reinforce the message (SAM). Apart from that, some of the ENGOs try to appeal public's emotions in their messages (Ecoknights \& MNS), performing repetition of messages to show that the issues are serious and important (GEC \& WWFM), finding issues that different from other organisation (ENSEARCH), choosing 
issues that concerned the public (Reef Check Malaysia \& SWCS) and asking the public to share information and environmental messages that are posted by ENGOs on Facebook with their families and friends (WWP). Overall, all of the participating ENGOs admitted that, Facebook is an effective delivery medium of information if it is use wisely.

\section{Conclusion}

Facebook status as the most popular communication medium used every day by Malaysian and it gives an opportunity and space for ENGOs in their effort to disseminate environmental messages quickly and clearly to a lot of people. Facebook is also trusted by ENGOs as an effective delivery medium of information to society because of the advantages and benefits that is provided in Facebook itself. In looking at the relationship between the uses of Facebook by ENGOs in disseminating environmental messages to society with the five principles of Dialogic Communication Theory, it shows that, these five principles were applied by ENGOs in building the relationship with the society.

Based on the first principle which is the dialogic loop, this principle was applied by ENGOs when the process of giving and sharing information occurred between ENGOs and society. The process of giving and sharing information is not only given and shared by ENGOs but the society also gives and shares the information with ENGOs in the ENGOs Facebook page. The society and ENGOs get benefits and goodness from the process of giving and sharing information that occurs between them.

The second principle in this theory which is the usefulness of information was applied perfectly by the ENGOs. This are clearly illustrated through the provision of useful information about environmental issues that became the focus of ENGOs to show and inform to society that was presented in a complete, detailed and creative way. Besides that, the usefulness of information that was served to society by the ENGO were the issues that ENGO know very well and the expertise was delivered to society in order to increase public knowledge and awareness of environmental issues that is related with their lives. Furthermore, the information that is provided by ENGOs can be used by society to deal with the environmental issues that affect them directly.

Refer to the third principle which is the ease of the interface, this principle was being applied very well by the ENGOs when the ENGOs provided certain features for environmental messages delivered to society to facilitate the society to see and understand the message conveyed by the ENGOs. Other than that, the ENGOs also adapt various methods to increase the creativity of the environmental messages that is delivered in Facebook to attract the society to accept the message effectively. The ENGOs has also applied the fourth principle which is the generation of return visits. This can be seen when the ENGOs use Facebook repeatedly in disseminating environmental messages to society. The frequency of Facebook use by ENGOs is on a daily, weekly and monthly basic. In addition, to ensure the messages conveyed through Facebook give an impact to society, the ENGOs has adopted various methods which include providing features and also other creative messages in delivering environmental messages to society.

The last principle which is the rule of conversation of visitors is being applied by the ENGOs. In this case, various strategies have been taken by the ENGOs in ensuring environmental messages that are being conveyed by them in Facebook are accepted and understood by society. The strategies used by ENGOs were tailored with society's interest to ensure the environmental messages can be delivered effectively to them. Overall, this study found that Facebook can be an effective tool in disseminating environmental messages to society through its capacities and capabilities and also when it is used wisely and comprehensively. Besides that, the effectiveness of Facebook in disseminating environmental messages to society also depends on how Facebook is used by the relevant ENGOs.

\section{REFERENCES}

[1] Juliana, A.W. and Nur 'Aainaa, Z., Public understanding towards environmental issues: a study on Malaysian television audience, in Hamidah, A.H., Azman, A.A., Jamilah, A. \& Nik Norma, N.H. (Ed.), Communication and environment: sustainability and risks (Penang: Penerbit USM) 136-162.

[2] Jamilah, A, Hasrina, M., Hamidah, A.H. and Juliana, A.W., Pengetahuan, sikap dan amalan masyarakat Malaysia terhadap isu alam sekitar, Jurnal Akademika, 81(3), 2011, 103-115.

[3] Adnan, H., Nik Norma, N.H and Azlan, A.R., River discourses in Malaysia: the case of Kinabatangan, Batu Pahat and Juru, in Hamidah, A.H., Azman, A.A., Jamilah, A. and Nik Norma, N.H. (Ed.), Communication and environment: sustainability and risks (Penang: Penerbit USM, 2012) 199-221.

[4] Osbaldiston, R. and Schott, J.P., Environmental sustainability and behavioural science: Meta-analysis of proenvironmental behaviour experiments, Journal of Environment and Behaviour, 44(2), 2012, 257-299.

[5] Zul Azmi, Y. and Zailan, M., Hak asasi manusia (Human Rights) dalam menangani krisis alam sekitar: Perspektif Seyyed Hossein Nasr, International Journal of Islamic Thought, 2, 2012, 80-90.

[6] Birsen, H. and Birsen, O., How has environmental news coverage changed, in Hamidah, A.H., Azman, A.A., Jamilah, A. and Nik Norma, N.H. (Ed.), Communication and environment: sustainability and risks (Penang: Penerbit USM, 2012) 39-49.

[7] Rohani, H., Mariani, A.A, Mohamad, M.Y., Kamaliah, S., Ramli, M., Adnan, H. and W, C.J., The environmental non-governmental organizations (ENGOs) in Malaysia Northern Region: their roles in protecting water resources, International NGO Journal, 5(7), 2010, 167-170. 
[8] Rusli, M. and Sheikh Abu Bakar, A., Why join an environmental NGO? A case study of the Malaysian Nature Society, Pertanika Journal Social Sciences \& Human, 13(1), 2005, 9-46.

[9] Mohd Shamsuriyadi, M. (2010, Mac 17). Guna facebook secara positif. Utusan Malaysia. Retrieved from http://www.utusan.com.my/utusan/info.asp? $\mathrm{y}=2010 \& \mathrm{dt}=0317 \& \mathrm{pub}=$ Utusan_Malaysia\&sec=Rencana\&pg=re_06.htm).

[10] Facebook cetus fenomena sedunia, berjaya bentuk 'wilayah' sendiri. (2010, Jun 15). Berita Harian. Retrieved from http://www.bharian.com.my/bharian/articles/Facebookcetusfenomenasedunia_berjayabentuk_8216_wilayah_8217_sendiri/Articl e).

[11] Das, B. and Sahoo, J.S., Social networking sites - a critical analysis of its impact on personal and social life, International Journal of Business and Social Science, 2(14), 2011, 222-228.

[12] Collier, A. and Magid, L., A parents' guide to facebook revised 2012 edition (ConnectSafely: I keep safe, 2012).

[13] Siti Ezaleila, M. and Azizah, H., Media sosial: Tinjauan terhadap laman jaringan sosial dalam talian tempatan, Jurnal Pengajian Media Malaysia, 12(2), 2010, 37-52.

[14] Statistics number of Malaysian who joining Facebook until November 2012. (http://www.socialbakers.com/facebook- statistics/). Retrieved on 26 November 2012.

[15] List of top 100 websites accessed by Malaysian society. (http://www.alexa.com/topsites/countries/MY). Retrieved on 26 November 2011.

[16] Gunter, S.K., Teach yourself facebook (United States of America: Pearson Education, 2011).

[17] Susilo, A., Use of facebook for academic learning in Universitas Terbuka - Indonesia, AAOU Journal, 3(2), $2008,99-114$.

[18] Lee, J.W.Y., Kim, B., Lee, T.L and Kim, M.S., Uncovering the use of facebook during the exchange program, China Media Research, 8(4), 2012, 62-67.

[19] Sheldon, P., The relationship between unwillingness-to-communicate and student's facebook use, Journal of Media Psychology, 20(2), 2008, 67-75.

[20] Shih, C., The facebook era: tapping online social networks to market, sell, and innovate (United States: Pearson Education, 2011.

[21] Mazer, J.P., Murphy, R.E. and Simonds, C.J., The effects of teacher self-disclosure via facebook on teacher credibility, Journal Learning, Media and Technology, 34(2), 2009, 175-183.

[22] Jauhariatul Akmal and Jamilah, A., Penggunaan facebook oleh badan bukan kerajaan alam sekitar (ENGO) dalam menyampaikan mesej alam sekitar kepada masyarakat, Malaysian Journal of Communication, 27 (2), 2010, 161-182.

[23] Carrera, C. Y., Chiu, P., Pratipwattanawong, S., Chienwattanasuk, S.F.S. Ahmad and Murphy, J., My space, my friends, my customers, in P. O'connor, W. Hopken and U. Gretzel, (ed.), Information and communication technologies in tourism 2008 (Springer Verlag Wien: Vienna, 2008) 94-105.

[24] Braun, V. and Clarke, V., Using thematic analysis in psychology, Qualitative Research in Psychology, 3(2), $2006,77-101$. 